19 Jacobson RL, Brewer A, Eis A, Siddiqi TA, Myall L. Transfer of aspirin across the perfused human placental cotyledon. Am $\mathcal{F}$ Obstet Gynecol 1991; 165: 939-44.

20 Hendricks S, Sarensen TK, Wong KY, et al. Doppler umbilical artery waveform indices - normal values from fourteen to forty-two weeks. Am $\mathcal{f}$ Obstet Gynecol 1989; 161: 761-5.

21 Templeton AGB, Whittle MJ, McGrath JC. The role of endogenous thromboxane in contractions to U46619, oxygen, 5-HT and 5-CT in the human isolated umbilical artery. Br f Pharmacol 1991; 103: 1079-84.

22 Templeton AGB, Kingdom JCP, Whittle MJ, McGrath JC. Contractile responses of the human umbilical artery from pregnancies complicated by responses of the human umbilical artery from pregnancies con

23 Leiser R, Kosanke G, Kaufmann P. Human placental vascularization: structural and quantitative aspects. In: Soma $\mathrm{H}$, ed. Placenta - basic science for clinical application. Tokyo: Karger publications, 1991.

24 Fairlie FM, Moretti M, Walker JJ, Sibai BM. Determinants of perinatal outcome in pregnancy-induced hypertension with absence of end-diastolic frequencies. Am $₹$ Obstet Gynecol 1991; 164: 1084-9.

25 Laurin J, Lingman G, Marsal K, Persson P-H. Fetal blood flow in pregnancies complicated by intrauterine growth retardation. Obstet Gynecol 1987; 69: 895-902.

26 Nicolini U, Nicolides P, Fisk NM. Limited role of fetal blood sampling in prediction of outcome in intrauterine growth retardation. Lancet 1990; 336: 768-82.

27 Escobar GJ. Prognosis of surviving very low birthweight infants: still in the dark. Br ₹ Obstet Gynaecol 1992; 99: 1-4.

28 Giles WB, Trudinger BJ, Baird P. Fetal umbilical artery flow velocity waveforms and placental resistance: pathological correlation. $\mathrm{Br}$ f Obstet Gynaecol 1985; 92: 31-8.

29 McCowan LM, Mullen BM, Ritchie K. Umbilical artery flow velocity waveforms and the placental vascular bed. Am $\mathcal{f}$ Obstet Gynecol 1987; 157: 900-2.

30 Morrow RJ, Bull S, Ritchie JWK. Pathological basis of abnormal Doppler waveforms. In: Pearce $M$, ed. Doppler ultrasound in perinatal medicine. London: Churchill Livingstone, 1992.

31 Wilcox GR, Trudinger BJ. Fetal platelet consumption: a feature of placental insufficiency. Obstet Gynecol 1991; 77: 616-21.

32 Van den Hof MC, Nicolaides KH. Platelet count in normal, small, and anemic fetuses. Am ₹ Obstet Gynecol 1990; 162: 753-9.
33 Hartikainen-Sorri A-L, Vuolteenaho O, Leppaluoto J, Ruskoaho H. Endothelin in umbilical artery vasospasm. Lancet 1991; 337: 619.

34 Douglas SA, James S, Hiley CR. Endothelial modulation and changes in endothelin presser activity during hypoxia in the rat isolated perfused superior mesenteric arterial bed. Br $\mathcal{f}$ Obstet Gynaecol 1991; 103: 1441-8.

35 Robillard JE, Weitzman RE, Burmeister L, Smith FG. Developmental aspects of the renal response to hypoxemia in the lamb fetus. Circ Res 1981; 48: $128-38$

36 Kingdom JCP, McQueen J, Connell JMC, Whittle MJ. Fetal angiotensin II levels and vascular (type I) angiotensin receptors in pregnancies complicated by intrauterine growth retardation. Br 7 Obstet Gynaecol 1993; 100: 476-83.

37 Lever AF. Slow pressor mechanisms in hypertension: a role for hypertrophy of resistance vessels. $\mathcal{F}$ Hypertens $1986 ; 4$ : 515-24.

38 Fok RY, Pavlova Z, Benirschke K, Paul R, Platt LD. The correlation of arterial lesions with umbilical artery Doppler velocimetry in the placentas of small-for-dates pregnancies. Obstet Gynecol 1990; 75: 578-83.

39 Abitol MM, La Gamma, Demeter E, Cipollina CM. Umbilical flow in the normal and pre-eclamptic placenta. Acta Obstet Gynecol Scand 1987; 66: 689-94.

40 Nordenvall M, Ullberg I, Laurin J, Lingman J, Sandstedt B, Ulmsten U. Placental morphology in relation to umbilical artery blood velocity waveforms. Eur F Obstet Gynecol Reprod Biol 1991; 40: 179-90.

41 Mironov VA, Katcher OV, Lebedeva IM. Three-dimensional morphology of placental villous tree and anthropometric estimations of newborns from placental villous tree and anthropometric estimations of newb

42 Gennser G, Rymark P, Isberg PE. Low birthweight and risk of high blood pressure in adulthood. $B M$ F 1988 ; $298: 1498-9$.

43 Williams S, St George IM, Silva PA. Intrauterine growth retardation and blood pressure at age seven and eighteen. $\mathcal{F}$ Clin Epidemiol 1992; 45: 1257-63.

44 Barker DJP, Bull AR, Osmond C, Simmonds SJ. Fetal and placental size and risk of hypertension in adult life. $B M \mathcal{F} 1990 ; 301: 259-62$

45 Barker DJP, Osmond C, Golding J, Kuh D, Wadsworth MEJ. Growth in utero, blood pressure in childhood and adult life, and mortality from cardiovascular disease. BMF 1989; 298: 564-7.

46 Morton J, Beattie EC, MacPherson F. Angiotensin II receptor antagonist Losatan has persistent effects on blood pressure in the young spontaneously hypertensive rat: lack of relation to vascular structure. $\mathcal{F}$ Vasc Res 1992; 29: 264-9.

\title{
The TORCH screen and intrauterine infections
}

TORCH (toxoplasmosis, rubella, cytomegalovirus, and herpes) screening has become almost synonymous with the investigation of an unexpected small for dates and/or premature infant with or without other abnormalities, and of apparently unknown cause. If no further direction is given to the house officer, he or she will embark on a series of unnecessary tests and may compound the error by sending inappropriate samples. The futility of such an approach has already been highlighted in a recent editorial. ${ }^{1}$ The aim of this annotation is to further hasten the demise of the 'TORCH screen' by considering three specific areas. Firstly, to consider the presentation of congenital infections and to stress that there are now more congenital infections than were originally encompassed by the term TORCH. Rather than expand the screening test clinicians should be aware that many infections present with specific clinical pictures and they should direct investigations accordingly. Secondly, to emphasise the rarity of any congenital infection and thus the poor yield of the blunderbuss approach of the TORCH screen. Thirdly, to consider whether antenatal diagnosis will reduce or even eliminate the need for neonatal TORCH screening.

\section{(1) Postnatal presentation}

To request a TORCH screen on a neonate suggests that certain abnormalities are characteristic of congenital infection and the clinical presentation of different agents is similar. Neither supposition is watertight. For example, although growth retardation can occur in congenital herpes $^{2}$ or syphilis, 50 infants with cytomegalovirus infection had weights and head circumferences that did not differ significantly from those of 97 controls. ${ }^{3}$ In addition, HIV infection, except in babies of seropositive mothers from Zaire, ${ }^{4}$ has not been associated with growth retardation. ${ }^{5}$ Prematurity is not a sine qua non of congenital infection, although typical of congenital syphilis, it is not increased by cytomegalovirus infection. Investigation of a small for dates or premature infant is extremely unlikely to identify any of the congenital infections. Only 10 to $15 \%$ of infants infected by toxoplasmosis during pregnancy have abnormalities in the neonatal period, ${ }^{6}$ even though $50 \%$ develop neurological sequelae or chorioretinitis by the age of 20 years. ${ }^{7}$ Parvovirus infection is associated with nonimmune hydrops, but rarely causes congenital malformation, ${ }^{8}$ indeed there is only one report of a fetal eye anomaly. ${ }^{9}$

Clinical signs that are presumed to be a non-specific clue to congenital infection may, in fact, be characteristic of one particular agent. Syphilis presents with many of the signs expected from a TORCH infection, a vesicular and erythematous skin rash, petechiae, severe non-haemolytic anaemia, and hepatosplenomegaly. In addition, the infant may suffer intestinal malfunction due to syphilitic enterocolitis, respiratory distress because of prematurity and/or pneumonia alba. The associated condylomata are, however, specific as are, in $95 \%$ of infants with congenital syphilis, the characteristic long bone changes (symmetrical metaphyseal lesions, horizontal bands of increased/ decreased radiodensity, and peripheral porosis. ${ }^{10}$ The diagnosis will be further advertised by the peeling of the soles of the feet and palms of the hands and can be confirmed by isolation of the spirochaete from the vesicular lesions. Reliance on the clinical signs described by the TORCH syndrome to identify congenitally infected infants could result in underdiagnosis of other including more recently described infections. Infants with listeriosis may present solely with septicaemia or an unusual pneumonia ${ }^{11}$ and this infection should be considered in the differential diagnosis of any infant presenting with septicaemia and/or pneumonia, particularly if premature labour has been complicated by meconium stained liquor. 


\section{(2) How common are the congenital infections?}

Screening tests are of value when the disease prevalence is high, yet the majority of congenital infections are extremely uncommon. Between 1975 and 1988, only 34 of 91 reported cases of toxoplasmosis infection could be definitely classified as due to congenital infection. ${ }^{12}$ In recent years, perinatal listeriosis has received publicity but this infection affects only one in 20000 . Prospective screening of 3315 pregnant women revealed only nine to have cytomegalovirus infection, four primary and five recurrent. ${ }^{13}$ Infection does not necessarily equate with neonatal illness, only $5 \%$ of the 1800 children born alive each year in England and Wales congenitally infected with cytomegalovirus will develop cytomegalic inclusion disease and a further $5 \%$ serious handicaps later. ${ }^{14}$ In the USA, although cytomegalovirus is the commonest congenital infection affecting 30000 to 40000 liveborn infants annually, only 1500 to 4000 per year are severely damaged.

It is important, however, to be aware of the variation between countries in the incidence of certain types of infection. In the UK, congenital toxoplasmosis occurs in between 1 to 2 per 1000 live births, but in other countries affects as many as 3 to 6 per 1000 births. ${ }^{15}$ The latter figure has influenced countries such as France and Austria to hold national antenatal screening programmes. Only 36 neonatal herpes infections were reported in the two year period 1987-8, giving a rate of 1 in 33000 births in the UK ${ }^{16}$ but, in the USA, the rate recently increased to one in $5000 .{ }^{17}$ Differences in the occurrence of congenital syphilis are even more marked. Against a background of 68786 pregnant women, only six affected children under 2 years of age were reported between 1981 to 1987 in the Mersey region. ${ }^{18}$ In contrast, in Johannesburg, where maternal syphilis is present in $7.6 \%$ of pregnancies and $2.5 \%$ of women at delivery, during a six month period in 1985 there were 41 infected fetuses ( 18 aborted or stillborn and 23 symptomatic at birth) from 9071 patients. ${ }^{10}$ Syphilis occurred in neonates at a rate of 0.05 to $0.45 \%$ and was the primary cause of death in between 2.8 and $10.5 \%$ of neonates. ${ }^{19}$ In the USA, syphilis is reported currently to be an important problem with a $95 \%$ increase in the number of cases between 1987 and $1989 .^{20}$

\section{(3) Antenatal diagnosis}

The likely impact of antenatal diagnosis in reducing the need for neonatal TORCH screening depends whether a congenitally infected fetus will have obvious abnormalities in utero, if the maternal infection is asymptomatic can sufficiently high risk groups be identified and the reliability of the tests used.

\section{(A) ANTENATAL PRESENTATION}

Some infections do cause abnormalities that can be detected on routine antenatal ultrasonography. Parvovirus B19 infection should be considered in the differential diagnosis of non-immune hydrops appearing in the second trimester. ${ }^{21}$ Cytomegalovirus infection can result in hydrops, placentamegaly, polyhydramnios, microcephaly and (secondary) pulmonary hypoplasia, ${ }^{22}$ a combination of fetal ascites and intrahepatic calcification ${ }^{23}$ and, rarely, only fetal meconium peritonitis. ${ }^{24}$ Ultrasonography, however, will not detect all infected fetuses. Although syphilis is associated with polyhydramnios, hydrops and a large placenta, infection late in the third trimester can result in an infant asymptomatic at birth, the signs of congenital syphilis developing only over the first few months. The hydrocephalus and intracranial calcification of the 'classical' triad of toxoplasmosis can be detected by ultrasonography, but only in $10 \%$ of cases is this apparent even at birth. In listeriosis, the presentation is nonspecific, reduction in fetal movements and a poor biophysical profile score. ${ }^{25}$

Maternal symptomatology is not a good guide to prognosis and, therefore, the need for screening. Symptomatic or asymptomatic rubella acquired in the first four months of pregnancy results in the same morbidity. ${ }^{26}$ Congenitally acquired disease can follow asymptomatic maternal infection. ${ }^{27}$ It should also be remembered that a history of previous rubella infection or immunisation cannot, with certainty, exclude the possibility of an infected fetus as reinfection and vaccination failure do occur.

\section{(B) HIGH RISK GROUPS}

High risk groups for certain infections can be identified but, for HIV and hepatitis B infection, this involves large numbers. Prostitutes, intravenous drug abusers, the sexual partners of bisexual men, or those who have received blood clotting factors are all at increased risk of HIV infection. The screening net must be widened for hepatitis B virus to include not only the groups described above but also mothers with a recent history of jaundice, ${ }^{28}$ white people from southern and eastern Europe, and ethnic groups other than white people from outside Europe. Although women at high risk from cytomegalovirus infection are those that are non-immune, as this amounts to $50 \%$ of women of childbearing age, ${ }^{29}$ screening for such patients is not a realistic method of eliminating the need for one component of the neonatal TORCH screen.

\section{(C) RELIABILITY OF ANTENATAL INVESTIGATION}

Accurate antenatal tests are highly desirable but, unfortunately, toxoplasmosis IgM has a poor specificity to detect women actively infected, $20 \%$ of whom after 20 weeks of gestation will transmit the infection to their fetus. The IgM is not necessarily indicative of recent infection and can persist for years, as a consequence further investigation is only required of mothers who seroconvert during pregnancy or have an initially high antibody titre. This has involved isolation of the parasite by means of mouse inoculation and results may not be available for four or five weeks. The combination of amniocentesis and placenta culture from transabdominal chorion villus sampling (which has a positive predictive value of $90 \%$ ) may reduce the waiting period to five days, but the case so far reported ${ }^{30}$ had overwhelmingly fatal infection. The yield of antenatal screening for toxoplasmosis may be improved by a combination of ultrasound screening, amniocentesis, funipuncture (cordocentesis), recently successful in 44 of 49 pregnancies. In addition, detection in the fetus of an increase in lymphocytes with the surface phenotype of $T$ cytotoxic suppressor cell $\mathrm{CD} 8+$, as occurs in infected adults, may facilitate antenatal diagnosis. ${ }^{31}$ The usefulness of cytomegalovirus specific IgM is also controversial..$^{32} 33$ The IgM can persist for up to four months after the acute episode and thus the infection could have been acquired before pregnancy, which is associated with negligible risk to the fetus. Detection of cytomegalovirus specific IgM or quantification of IgG antibodies in early pregnancy does not differentiate those more likely to give birth to a damaged child, thus screening asymptomatic patients appears to have little value. ${ }^{34}$

Antenatal detection of maternal or even fetal infection does not necessarily imply a damaged infant. None of the fetuses of 39 mothers prospectively followed up who had serological evidence of recent human parvovirus B19 infection developed hydrops. ${ }^{35}$ Only one in 10 fetuses of confirmed intrauterine cytomegalovirus infection will be 
damaged, ${ }^{36}$ thus prenatal diagnosis, if it is simply picking up the virus in amniotic fluid or a raised $\operatorname{IgM}$, is of very limited prognostic value. Negative results from screening should not be too reassuring as in congenital spyhilis, for which antenatal screening is cost effective at an incidence as low as 5 per 100000,37 investigation must also occur after delivery, as seronegative mothers may convert and present with syphilis at delivery and reinfection can occur. ${ }^{38}$

\section{Conclusion}

In the UK, the low occurrence rate of congenital infection means that TORCH screening in its entirety cannot be cost effective. Both the fetus and the neonate should always be investigated appropriately for specific infections and only when congenital infection is a serious contender in the differential diagnosis. Antenatal investigation can give the paediatrician prior warning of an infected neonate, but we must be aware of the shortcomings of such tests and the varied outcome of apparent infection detected in utero.

Department of Child Health,

ANNE GREENOUGH

King's College School of Medicine and Dentistry,

4th Floor, New Ward Block,

King's College Hospital,

London SE5 $9 R S$

1 Anonymous. TORCH syndrome and TORCH screening. Lancet 1990; i: 1559-61.

2 Nahmias AJ, Josey WE, Naib ZM, Freeman MG, Fernandez RJ, Wheeler JH. Perinatal risk associated with maternal genital herpes simplex virus infection. Am $\mathcal{F}$ Obstet Gynecol 1971; 110: 825-37.

3 Preece PM, Pearl KN, Peckham CS. Congenital cytomegalovirus infection. Arch Dis Child 1984; 59: 1120-6.

4 Ryder RW, Nsa W, Hassig SE, et al. Perinatal transmission of the human immunodeficiency virus type 1 to infants of seropositive women in Zaire. immunodeficiency virus type 1 to infa

5 Blanche S, Rouzioux C, Moscato MLG, et al and the HIV Infection In Newborns French Collaborative Study Group. A prospective study of infants born to women seropositive for human immunodeficiency virus type I. N Engl f Med 1989; 329: 1643-8.

6 Koskiniemi M, Lappalainen M, Hedman K. Toxoplasmosis needs evaluation. Am $\mathcal{F}$ Dis Child 1989; 143: 724-8.

7 Foulon W, Naessens A, Mahler T, de Waele M, de Catte L, de Meuter F. Prenatal diagnosis of congenital toxoplasmosis. Obstet Gynecol 1990; 76: 769-72.

8 Anonymous. Risks associated with human parvovirus B19 infection. MMWR. Morb Mortal Wkly Rep 1989; 38: 81-97.

9 Weiland HT, Vermey-Keers C, Salimans MMM, Fleuren GJ, Verwey RA Parvovirus B19 associated with fetal abnormality. Lancet 1987; i: 682-3.

10 Venter J, Pettifor JM, Exposto F, Sefuba M. Congenital syphilis - who is at risk? S Afr Med $¥$ 1989; 76: 93-5.

11 Lissauer TJ, Shaw PJ, Underhill G. Neonatal herpes simplex pneumonia. Arch Dis Child 1984; 59: 668-70.
12 Hall SM. Congenital toxoplasmosis in England, Wales and Northern Ireland: some epidemiological problems. $B M \mathcal{F} 1983 ; 287: 453-5$.

13 Griffiths $\mathrm{PD}$, Baboonian C. A prospective study of primary cytomegalovirus infection during pregnancy: final report. Br $\mathcal{F}$ Obstet Gynaecol 1984; 91: 307-15.

14 Best JM. Congenital cytomegalovirus infection. BMf 1987; 294: 1440-1.

15 Foulon W, Naessens A, Volckaert M, Lauwers S, Amy J. Congenital toxoplasmosis: a prospective survey in Brussels. Br f Obstet Gynaecol 1984; 91: 419-23.

16 Lissauer T, Jeffries D. Preventing neonatal herpes infection. Br $\mathcal{F}$ Obstet Gynaeol 1989; 96: 1015-23.

17 Whitley RJ. Herpes simplex virus infections. In: Klein JO, Remington JS, eds. Infectious diseases of the fetus and newborn infant. Philadelphia: W B Saunders, 1987.

18 Holland EFN, O'Mahony CP. Is it time to review antenatal screening for syphilis? Brf Obstet Gynecol 1989; 96: 1005-6.

19 Delport SD. Guidelines for the diagnosis and treatment of maternal and congenital syphilis. Continuing Medical Education Monthly 1991; 9: $1261-77$.

20 Ikeda $M$, Jenson HB. Evaluation and treatment of congenital syphilis. f Pediatr 1990; 117: 843-52.

21 Bond PR, Caul EO, Usher J, Cohen BJ, Clewley JP, Field AM. Intrauterine infection with human parvovirus. Lancet 1986; i: 448-9.

22 Stocker JT. Congenital cytomegalovirus infection presenting as massive ascites with secondary pulmonary hypoplasia. Hum Pathol 1985; 16: 1173-5

23 Yamashita Y, Iwanaga R, Goto A, et al. Congenital cytomegalovirus infection associated with fetal ascites and intrahepatic calcifications. Acta Paediatr Scand 1989; 78: 965-7.

24 Pletcher BA, Williams MK, Mulivor RA, Barth D, Linder C, Rawlinson K Intrauterine cytomegalovirus infection presenting as fetal meconium peritonitis. Obstet Gynecol 1991; 78: 903-4.

25 Liner RI. Intrauterine listeria infection: prenatal diagnosis by biophysical assessment and amniocentesis. Am F Obstet Gynecol 1990; 163: 1596-7.

26 Miller E. Rubella infection in pregnancy: remaining problems. Br f Obstet Gynaecol 1989; 96: 887-92.

27 Best JM, Banatvala JE, Morgan-Capner P, Miller E. Fetal infection after maternal reinfection with rubella: criteria for defining reinfection. $B M \mathcal{\jmath}$ 1989; 299: 773-5.

28 Hoofnagle JH. Toward universal vaccination against hepatitis B virus. N Engl f Med 1989; 321: 1333-4.

29 Klapper PE, Morris DJ. Screening for viral and protozoal infections in pregnancy: a review. Br f Obstet Gynaecol 1990; 97: 974-83.

30 Foulon W, Naessens A, de Catte L, Amy JJ. Detection of congenital toxoplasmosis by chorionic villus sampling and early amniocentesis. $\mathrm{Am} \mathcal{F}$ Obstet Gynecol 1990; 163: 1511-3.

31 Lecoher B, Marion S, Deroum F, Daffos F, Sarrot G. T-cell subpopulations of fetuses infected by Toxoplasma gondii. Eur $\mathcal{f}$ Clin Microbiol Infect Dis 1989; 8: 572-3.

32 Griffiths PD, Stagno S, Pass RF, Smith RJ, Alford CA. Infection with cytomegalovirus during pregnancy: specific IgM antibodies as a marker of recent primary infection. $\mathcal{F}$ Infect Dis $1982 ; 145: 647-53$.

33 Morris DJ. Congenital cytomegalovirus infection. BMF 1987; 295: 269-70.

34 Griffiths PD, Baboonian C, Rutter D, Peckham C. Congenital and maternal cytomegalovirus infections in a London population. Br $\mathcal{f}$ Obstet Gynaecol 1991; 98: 135-40.

35 Rodis JF, Quinn DL, Gary GW, et al. Management and outcomes of pregnancies complicated by human B19 parvovirus infection: a prospective study. Am F Obstet Gynecol 1990; 163: 1168-71.

36 Peckham CS, Logan S. Cytomegalovirus infection in pregnancy. In: Cosmi EV, Renzo GC, eds. Proceedings of the 11th European Congress of Perinatal Medicine. Chur, Switzerland: Harwood, 1988: 255-60.

37 Stray-Pedersen B. Economic evaluation of maternal screening to prevent congenital syphilis. Sex Transm Dis 1983; 10: 167-72.

38 Delport SD, Adhikari M, van der Elst CW, Venter A. Congenital syphilis neglected medical problem. $S$ Afr Med F 1989; 76: 297-8. 